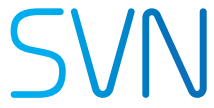

Stroke \& Vascular Neurology

\title{
Predictors of dysphagia screening and pneumonia among patients with acute ischaemic stroke in China: findings from the Chinese Stroke Center Alliance (CSCA)
}

\author{
Jianshu Liang, ${ }^{1}$ Zhike Yin (D) , ${ }^{1,2}$ Zixiao Li, ${ }^{3,4}$ Hongqiu Gu (D) , ${ }^{5}$ Kaixuan Yang, ${ }^{5}$ \\ Yunyun Xiong (D) , ${ }^{3}$ Yongjun Wang, ${ }^{3}$ Chunjuan Wang ${ }^{3}$
}

To cite: Liang J, Yin Z, Li Z, et al. Predictors of dysphagia screening and pneumonia among patients with acute ischaemic stroke in China: findings from the Chinese Stroke Center Alliance (CSCA). Stroke \& Vascular Neurology 2022;0. doi:10.1136/svn-2020-000746

- Additional supplemental material is published online only. To view, please visit the journal online (http://dx.doi.org/10. 1136/svn-2020-000746).

$\mathrm{JL}$ and $\mathrm{ZY}$ contributed equally.

$J L$ and $Z Y$ are joint first authors.

Received 12 November 2020 Accepted 7 December 2021

D) Check for updates

(c) Author(s) (or their employer(s)) 2022. Re-use permitted under CC BY-NC. No commercial re-use. See rights and permissions. Published by BMJ.

For numbered affiliations see end of article.

Correspondence to Chunjuan Wang; wangchunjuan@ncrcnd.org.cn

\section{ABSTRACT}

Background and purpose Guidelines recommend dysphagia screening to identify those at high risk of pneumonia. However, little is known about the prevalence and predictors of dysphagia screening and pneumonia among patients with acute ischaemic stroke in China. Methods Using data from the Chinese Stroke Center Alliance, which is a multicentre, prospective, consecutive patient enrolment programme, univariate and multivariate analyses were conducted to identify patient and hospital characteristics associated with dysphagia screening and pneumonia during acute hospitalisation.

Results 0 790811 patients admitted to 1476 hospitals, $622718(78.7 \%)$ underwent dysphagia screening, and 64398 (8.1\%) developed pneumonia. Patients in stroke units were more likely to be screened for dysphagia than those not in stroke units (OR 1.50; 95\% $\mathrm{Cl} 1.48$ to 1.52), while patients with a past history of stroke were less likely to be screened (OR 0.87; 95\% $\mathrm{Cl} 0.86$ to 0.88 ). Dysphagia screening (OR 1.46; $95 \% \mathrm{Cl} 1.30$ to 1.65), dysphagia (OR 7.31; $95 \% \mathrm{Cl} 7.15$ to 7.46 ), and admission to stroke units (OR 1.17; $95 \% \mathrm{Cl} 1.14$ to 1.19) were significantly associated with a greater risk of pneumonia.

Conclusions Dysphagia was a critical factor in the development of pneumonia. Nearly one in five patients with acute ischaemic stroke in the Chinese Stroke Center Alliance were not screened for dysphagia. Pneumonia prevention during acute hospitalisation is dependent not only on dysphagia screening but also on the effectiveness of subsequent dysphagia management interventions. Further studies are needed to elucidate the relationship between dysphagia screening, stroke unit care and pneumonia in patients with acute ischaemic stroke.

\section{INTRODUCTION}

Stroke remains the leading cause of death and disability in China. ${ }^{1}$ Pneumonia is a serious sequela affecting nearly $10 \%-40 \%$ of patients with stroke $\mathrm{e}^{2-4}$ and can compromise functional outcomes and increase the length of hospitalisation and the risk of mortality. ${ }^{56}$ Dysphagia, or difficulty swallowing, affects more than $70 \%$ of patients with stroke. ${ }^{7}$ It is regarded as a main causative factor involved in the development of pneumonia. ${ }^{8}$ The identification and management of dysphagia are crucial for improving stroke care quality and prognosis.

Dysphagia screening (DS) is a quick and minimally invasive procedure that assists with predicting dysphagia and determining the immediate risk of aspiration. A variety of screening tools have been developed for this purpose. Among them, instrument-based screening with videofluoroscopy or fibre-optic endoscopic evaluation of swallowing are the gold standards for the identification of aspiration in patients with stroke, ${ }^{9} 10$ but the water swallowing test is the simplest and most costeffective bedside screening tool available in practice.

Previous studies have shown that the early implementation of DS to identify patients with dysphagia followed by the prompt initiation of interventions is effective at preventing pneumonia. ${ }^{11}$ Guidelines for the management of patients with acute ischaemic stroke (AIS) recommend DS before oral intake, such as eating, drinking or receiving oral medications, to identify the risk of aspiration. ${ }^{13}{ }^{14}$ Furthermore, DS has been recognised as a key indicator of stroke care quality. ${ }^{15}$ However, data are limited on clinical practices and outcomes regarding DS among patients with AIS in China.

Using data from the Chinese Stroke Center Alliance (CSCA), we aimed to assess the factors associated with receiving DS and developing pneumonia during acute hospitalisation and the relationship between DS and pneumonia in patients with AIS.

\section{MATERIALS AND METHODS}

\section{Data sources}

The CSCA is a national, voluntary, multicentre, prospective, continuous quality 
improvement programme launched in 2015 by the Chinese Stroke Association under the guidance of the National Center of Neurological Diseases Care Management. Details of the design and implementation of the CSCA programme have been described elsewhere. ${ }^{16}$ All Chinese secondary and tertiary grade hospitals are eligible to join the programme and prospectively report demographic and clinical data on all consecutive patients with acute stroke. Information on hospital characteristics, including geographical region and hospital volume, was collected. The data coordination, extraction and analysis centre of the CSCA resides at the China National Clinical Research Center for Neurological Diseases, Beijing Tiantan Hospital, Capital Medical University. Participating hospitals were granted permission to report data without the consent of patients under the common rule or under a waiver of authorisation and exemption from their respective Institutional Review Boards, although individual patients' identities were kept anonymous to protect confidentiality as per national standards. ${ }^{16}$ The data that support the findings of this study are available on reasonable request.

\section{Patient characteristics}

Patient data were extracted from all CSCA hospitals from August 2015 to July 2019 and included those who met the following criteria: (1) aged 18 years or older and (2) had a primary diagnosis of AIS confirmed by brain CT or MRI. We excluded patients with a history of pulmonary infection within 2 weeks, admission to the intensive care unit (ICU) or neurological ICU (NICU) and death within 72 hours of admission. Based on the potential clinical relevance to DS and pneumonia, the following patient and hospital characteristics were included in this study: demographics (age and sex), arrival by emergency medical services (EMS), initial National Institute of Health Stroke Scale (NIHSS) score, admission location, medical history of diseases and health behaviours (smoking and alcoholism) and hospital characteristics.

\section{Exposures and outcome}

DS referred to the evaluation of swallowing function of patients by a healthcare professional before any oral intake, including food, liquid and medication. The $30 \mathrm{~mL}$ water swallowing test was used to screen for dysphagia at all participating hospitals. ${ }^{17}$ Dysphagia was described as difficulty eating and drinking, and levels III-V on the $30 \mathrm{~mL}$ water swallowing test (when patients experienced choking or coughing or were unable to drink) indicated the presence of dysphagia. Pneumonia was diagnosed by clinicians according to the Centers for Disease Control and Prevention criteria, with support from clinical, biochemical, microbiological and radiological evidence, such as fever, abnormal chest radiograph, hypoxaemia and isolation of a relevant pathogen, ${ }^{18}$ and identified on the clinical documentation as a discharge diagnosis.

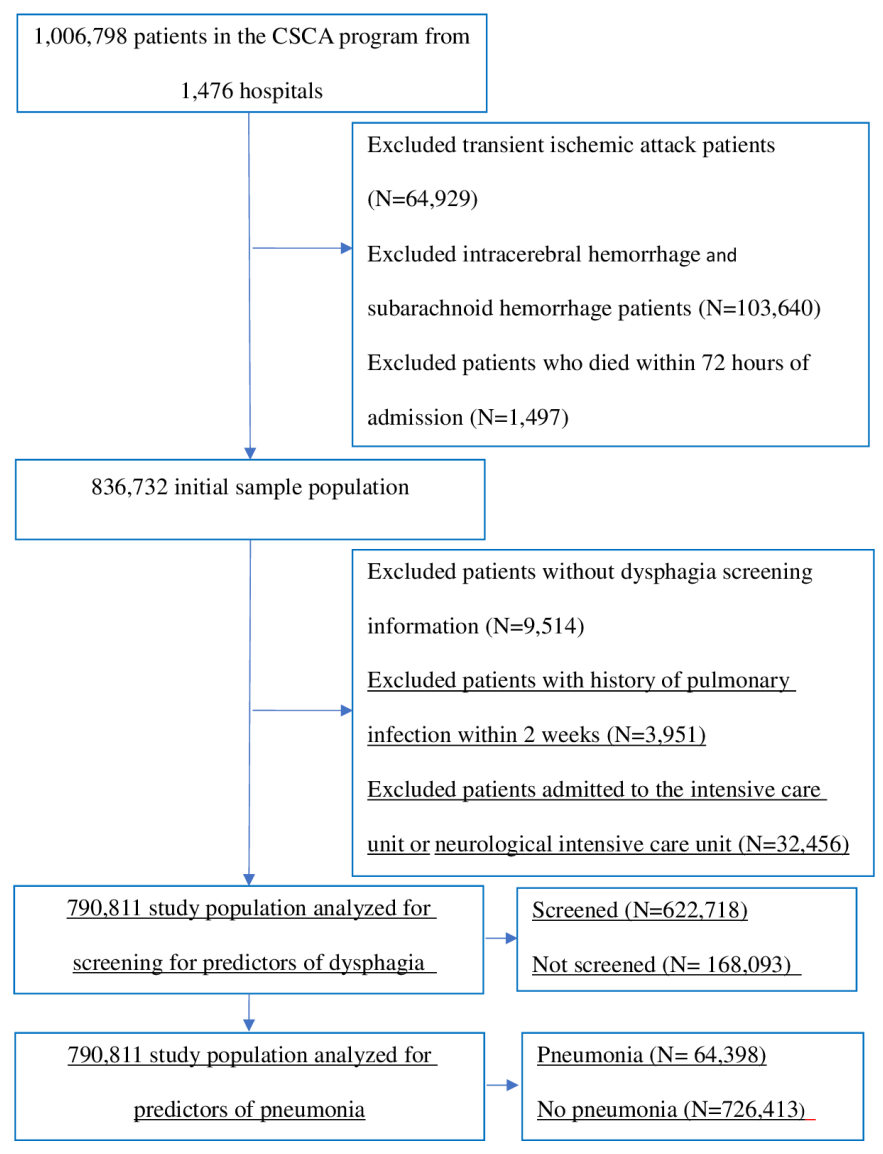

Figure 1 Patient flow chart. CSCA, Chinese Stroke Center Alliance.

\section{Statistical analysis}

Continuous variables are presented as the means with SD or medians with interquartile ranges. Categorical variables are presented as absolute numbers with percentages. Because of the large sample size, absolute standardised differences (ASDs) were used to compare differences in baseline characteristics between patients with and without DS or pneumonia. An ASD >10 indicated a statistically significant difference in the variable of interest between groups. ${ }^{19}$ Based on clinical experience, variables that may affect DS or pneumonia were also included in the multivariate analysis models. ORs and 95\% CIs were generated. Finally, we conducted a sensitivity analysis in a subset of the study population with initial NIHSS scores $(80.1 \%$ of the patients) and compared the results with those of the first model (ie, with all patients) to further assess the impact of stroke severity as a potential confounder. All tests were two tailed, and $\mathrm{p}<0.05$ was considered statistically significant. All statistical analyses were performed using SAS V.9.4 (SAS Institute).

\section{RESULTS}

A total of 790811 consecutive patients with AIS from 1476 hospitals were included in the final analytic sample, $622718(78.7 \%)$ of whom had documented DS, and $64398(8.1 \%)$ of whom developed pneumonia (figure 1). 
Table 1 Baseline characteristics of patients with and without DS

\begin{tabular}{|c|c|c|c|c|}
\hline Variables & $\begin{array}{l}\text { Total, } n(\%) \\
\mathrm{N}=790811\end{array}$ & $\begin{array}{l}\text { Documented DS, n (\%) } \\
\mathrm{N}=622718(78.7 \%)\end{array}$ & $\begin{array}{l}\text { No documented DS, } n(\%) \\
\mathrm{N}=168093(21.3 \%)\end{array}$ & ASD \\
\hline Age, mean (SE) & $66.2(12.0)$ & $66.2(12.0)$ & 65.8 (11.9) & 3.3 \\
\hline Male & $494756(62.6)$ & $390000(62.6)$ & $104756(62.3)$ & 0.6 \\
\hline Arrival by EMS & $82859(10.5)$ & $66569(10.7)$ & $16290(9.7)$ & 3.3 \\
\hline $\begin{array}{l}\text { Admission NIHSS score, median } \\
\left(\text { (IQR) }^{*}\right.\end{array}$ & $3.0(2.0-6.0)$ & $3.0(2.0-6.0)$ & $3.0(2.0-6.0)$ & 5.7 \\
\hline $0-3$ & $347950(44.0)$ & $290681(46.7)$ & $57269(34.1)$ & 25.9 \\
\hline $4-14$ & 251270 (31.8) & 211311 (33.9) & $39959(23.8)$ & 22.4 \\
\hline$\geq 15$ & $34051(4.3)$ & $27072(4.3)$ & $6979(4.2)$ & 0.5 \\
\hline Hospitalised in SUs & $193968(24.5)$ & $162518(26.1)$ & $31450(18.7)$ & 17.8 \\
\hline \multicolumn{5}{|l|}{ Medical history } \\
\hline Stroke/TIA & $263769(33.4)$ & $203928(32.7)$ & 59841 (35.6) & 6.1 \\
\hline Hypertension & $509975(64.5)$ & 405731 (65.2) & $104244(62.0)$ & 6.7 \\
\hline Diabetes mellitus & $170334(21.5)$ & 136209 (21.9) & $34125(20.3)$ & 3.9 \\
\hline Dyslipidaemia & $61111(7.7)$ & $47051(7.6)$ & $14060(8.4)$ & 2.9 \\
\hline $\mathrm{CHD} /$ previous MI & $69357(8.8)$ & $55383(8.9)$ & $13974(8.3)$ & 2.1 \\
\hline Atrial fibrillation & $39276(5.0)$ & $31983(5.1)$ & $7293(4.3)$ & 3.8 \\
\hline Carotid stenosis & $10288(1.3)$ & $8152(1.3)$ & $2136(1.3)$ & $<0.01$ \\
\hline PVD & $13775(1.7)$ & $10760(1.7)$ & $3015(1.8)$ & 0.8 \\
\hline Heart failure & $7884(1.0)$ & $6351(1.0)$ & $1533(0.9)$ & 1.0 \\
\hline Dementia & $3743(0.5)$ & $3096(0.5)$ & $647(0.4)$ & 1.5 \\
\hline Smoking & $293172(37.1)$ & $232940(37.4)$ & $60232(35.8)$ & 3.3 \\
\hline Alcoholism & $185420(23.4)$ & $147324(23.7)$ & $38096(22.7)$ & 2.4 \\
\hline \multicolumn{5}{|l|}{ Region } \\
\hline Eastern & $367586(46.5)$ & 294309 (47.3) & 73277 (43.6) & 7.4 \\
\hline Central & 258162 (32.6) & $194643(31.3)$ & $63519(37.8)$ & 13.7 \\
\hline Western & $165063(20.9)$ & $133766(21.5)$ & 31297 (18.6) & 7.2 \\
\hline \multicolumn{5}{|l|}{ Hospital grade } \\
\hline Secondary & $307090(38.8)$ & 239975 (38.5) & $67115(39.9)$ & 2.9 \\
\hline Tertiary & $483721(61.2)$ & $382743(61.5)$ & $100978(60.1)$ & 2.9 \\
\hline
\end{tabular}

*The NIHSS score was missing for 157540 (19.9\%) patients.

.ASDs, absolute standardised differences; CHD, coronary heart disease; DS, dysphagia screening; EMS, emergency medical services; MI, myocardial infarction; NIHSS, National Institute of Health Stroke Scale; PVD, peripheral vascular disease; SUs, stroke units; TIA, transient ischaemic attack.

\section{Predictors of DS}

The baseline characteristics of patients with and without documented screening are shown in table 1. Patients who underwent DS were more often admitted to stroke units (SUs) $(26.1 \%$ vs $18.7 \%)$, and more patients with mild or moderate strokes received DS $(46.7 \%$ vs $34.1 \%$ of those with a NIHSS score of 3 or less and $33.9 \%$ vs $23.8 \%$ of those with NIHSS scores from 4 to 14).

In multivariable analysis, patients who were admitted to SUs were more likely to receive DS (OR $1.50 ; 95 \% \mathrm{CI}$ 1.48 to 1.52 ), while patients with a history of stroke/transient ischaemic attack were less likely to receive DS (OR 0.87 ; $95 \%$ CI 0.86 to 0.88 ) (table 2 , column 2 ). To determine whether DS was associated with stroke severity, we performed a sensitivity analysis in the $80.1 \%$ of patients for whom the initial NIHSS score had been recorded. A higher admission NIHSS score was associated with not receiving DS (OR 0.99; 95\% CI 0.99 to 0.99 ) (table 2, column 4).

\section{Predictors of pneumonia}

The baseline characteristics of patients with and without pneumonia are shown in table 3. The proportion of patients who developed pneumonia was higher in those with older age ( $72.5 \pm 11.3$ years vs $65.6 \pm 11.9$ years), higher admission NIHSS score (median, 7 vs 3 ), arrival by EMS (22.0\% vs $9.5 \%)$, multiple comorbidities, DS performed prior to oral intake $(85.0 \%$ vs $78.2 \%)$, and dysphagia 
Table 2 Multivariable models of factors associated with documentation of DS

\begin{tabular}{|c|c|c|c|c|}
\hline \multirow[b]{2}{*}{ Variable } & \multicolumn{2}{|c|}{$\begin{array}{l}\text { Patients with and without NIHSS } \\
\text { scores, } N=790811\end{array}$} & \multicolumn{2}{|c|}{$\begin{array}{l}\text { Patients with NIHSS scores, } \\
\mathrm{N}=633271\end{array}$} \\
\hline & OR $(95 \% \mathrm{Cl})$ & $P$ value & OR $(95 \% \mathrm{Cl})$ & $P$ value \\
\hline Hospitalised in SUs & $1.50(1.48$ to 1.52$)$ & $<0.0001$ & $1.38(1.36$ to 1.40$)$ & $<0.0001$ \\
\hline \multicolumn{5}{|l|}{ Medical history } \\
\hline Stroke/TIA & 0.87 (0.86 to 0.88$)$ & $<0.0001$ & 0.89 (0.88 to 0.91$)$ & $<0.0001$ \\
\hline Hypertension & $1.16(1.14$ to 1.17$)$ & $<0.0001$ & 1.13 (1.11 to 1.14$)$ & $<0.0001$ \\
\hline Diabetes mellitus & $1.10(1.08$ to 1.11$)$ & $<0.0001$ & 1.10 (1.08 to 1.12$)$ & $<0.0001$ \\
\hline Atrial fibrillation & 1.19 (1.16 to 1.22$)$ & $<0.0001$ & 1.20 (1.16 to 1.24$)$ & $<0.0001$ \\
\hline Smoking & 1.09 (1.07 to 1.10$)$ & $<0.0001$ & $1.02(1.01$ to 1.04$)$ & 0.0006 \\
\hline Hospital grade (tertiary vs secondary) & $0.98(0.97$ to 1.00$)$ & 0.0061 & 0.97 (0.96 to 0.99$)$ & $<0.0001$ \\
\hline \multicolumn{5}{|l|}{ Region, Western (reference) } \\
\hline Eastern & 0.95 (0.94 to 0.97$)$ & $<0.0001$ & 1.00 (0.98 to 1.02$)$ & 0.8113 \\
\hline Central & $0.75(0.74$ to 0.76$)$ & $<0.0001$ & 0.81 (0.80 to 0.83$)$ & $<0.0001$ \\
\hline Admission NIHSS score (per 1-point increase) ${ }^{*}$ & - & - & 0.99 (0.99 to 0.99$)$ & $<0.0001$ \\
\hline
\end{tabular}

The first column includes all patients; the second column is restricted to patients with available admission NIHSS scores.

*Admission NIHSS score not included due to missing data in $19.9 \%$ of patients.

DS, dysphagia screening; NIHSS, National Institute of Health Stroke Scale; SU, stroke unit; TIA, transient ischaemic attack.

(35.6\% vs $5.5 \%$ ) (table 3). Regarding discharge outcomes, patients with pneumonia had higher in-hospital mortality ( $1.7 \%$ vs $0.1 \%)$, a longer length of stay (13 vs 11 days), and a higher proportion of patients with an $\mathrm{mRS}$ score of 3 or greater $(29.4 \%$ vs $13.9 \%)$ (table 3$)$.

Older age; arrival by EMS; a history of stroke, atrial fibrillation, heart failure and dementia; receiving DS; having dysphagia; having unknown swallowing function; and admission to SUs were significantly associated with higher odds of pneumonia (table 4). In the sensitivity analysis of 633271 patients who had a recorded admission NIHSS score, pneumonia was strongly associated with a higher NIHSS score at admission (OR 1.08; 95\% CI 1.07 to 1.08 ). There was little change in the direction or magnitude of the variables associated with the risk of pneumonia (table 4).

\section{DISCUSSION}

In this study, which involved nearly 800000 patients with AIS, we found that $78.7 \%$ of the patients received DS during hospitalisation, which is slightly lower than findings from previous studies showing the implementation rate of DS to be greater than $80 \% .{ }^{20}{ }^{21}$ In the HeadPoST programme, a multinational study conducted between March 2015 and November 2016, the frequency of DS was found to be $69.2 \%$ in China. ${ }^{8}$ Adherence to DS was improved because the CSCA provided an opportunity to increase adherence to evidence-based practices, and DS is widely carried out in hospitals nationwide. However, one in five patients with AIS were still not screened. Patients with a stroke history and a higher NIHSS score were less likely to receive DS, probably because severe stroke made early testing impossible or dysphagia was not a care priority. These patients were also at higher risk for pneumonia. Therefore, to prevent pneumonia, special attention should be paid to performing DS in these two groups of patients in clinical practice.

Pneumonia is a common complication in the early stage of stroke and leads to a worse prognosis. ${ }^{22}$ Our study revealed that $8.1 \%$ of patients with AIS developed pneumonia, which is consistent with what has been reported in the literature. ${ }^{2}$ Studies have also shown that older age, male sex, more severe stroke and comorbid coronary heart disease and atrial fibrillation are associated with pneumonia. ${ }^{23-25}$ However, dysphagia is the most significant predictor of pneumonia. ${ }^{26}$ International guidelines recommend screening patients with stroke for dysphagia prior to oral intake of food, liquid and/ or medications. ${ }^{1327} 28$ In addition, early management strategies following DS, such as dietary adaptations, oral hygiene and swallowing therapy, are also important for the prevention of pneumonia. Teuschl et al used GUSS to perform DS and guide dietary modifications in patients who had acute stroke and reported that the incidence of pneumonia was $5.2 \%$, suggesting that interventions based on the results of DS were effective at reducing the incidence of pneumonia. ${ }^{24}$ Additionally, in a Japanese singlecentre study, the implementation of a multidisciplinary swallowing team decreased the rate of pneumonia from $16 \%$ to $7 \% .^{29}$ It is important to note that patients' cognitive status may affect their understanding and compliance with dysphagia management strategies. As shown in this study, those with dementia have an increased risk of pneumonia. ${ }^{30}$ Future studies should aim to include cognitive impairment or dementia as an additional risk factor to ensure that these patients have the same opportunities for recovery. 
Table 3 Baseline characteristics of patients with and without pneumonia

\begin{tabular}{|c|c|c|c|c|}
\hline Variables & $\begin{array}{l}\text { Total, } \mathbf{n}(\%) \\
\mathrm{N}=790811\end{array}$ & $\begin{array}{l}\text { Pneumonia, } n(\%) \\
\mathrm{N}=64398(8.1 \%)\end{array}$ & $\begin{array}{l}\text { No pneumonia, } n(\%) \\
\mathrm{N}=726413(91.9 \%)\end{array}$ & ASD \\
\hline Age, mean (SE) & $66.2(12.0)$ & $72.5(11.3)$ & $65.6(11.9)$ & 60.3 \\
\hline Male & $494756(62.6)$ & 39435 (61.2) & $455321(62.7)$ & 3.1 \\
\hline Arrival by EMS & $82859(10.5)$ & $14191(22.0)$ & $68668(9.5)$ & 34.8 \\
\hline Admission NIHSS score, median (IQR) ${ }^{\star}$ & $3.0(2.0-6.0)$ & $7.0(3.0-13.0)$ & $3.0(1.0-5.0)$ & 80.4 \\
\hline $0-3$ & $347950(44.0)$ & $14169(22.0)$ & $333781(45.9)$ & 52.2 \\
\hline $4-14$ & $251270(31.8)$ & $26305(40.8)$ & 224965 (31.0) & 20.5 \\
\hline$\geq 15$ & $34051(4.3)$ & $11424(17.7)$ & $22627(3.1)$ & 49.3 \\
\hline Hospitalised in SUs & $193968(24.5)$ & $19280(29.9)$ & $174688(24.0)$ & 13.3 \\
\hline \multicolumn{5}{|l|}{ Medical history } \\
\hline Stroke/TIA & $263769(33.4)$ & $25103(39.0)$ & $238666(32.9)$ & 12.7 \\
\hline Hypertension & $509975(64.5)$ & $41991(65.2)$ & $467984(64.4)$ & 1.7 \\
\hline Diabetes mellitus & $170334(21.5)$ & $13879(21.6)$ & $156455(21.5)$ & 0.2 \\
\hline Dyslipidaemia & $61111(7.7)$ & $5341(8.3)$ & $55770(7.7)$ & 2.2 \\
\hline $\mathrm{CHD} /$ previous $\mathrm{MI}$ & $69357(8.8)$ & $8849(13.7)$ & $60508(8.3)$ & 17.3 \\
\hline Atrial fibrillation & $39276(5.0)$ & 8649 (13.4) & $30627(4.2)$ & 32.9 \\
\hline Carotid stenosis & $10288(1.3)$ & $1202(1.9)$ & $9086(1.3)$ & 4.8 \\
\hline PVD & $13775(1.7)$ & $1824(2.8)$ & $11951(1.6)$ & 8.2 \\
\hline Heart failure & $7884(1.0)$ & $2198(3.4)$ & $5686(0.8)$ & 18.2 \\
\hline Dementia & $3743(0.5)$ & $897(1.4)$ & $2846(0.4)$ & 10.6 \\
\hline Smoking & $293172(37.1)$ & 23127 (35.9) & $270045(37.2)$ & 2.7 \\
\hline Alcoholism & $185420(23.4)$ & $13755(21.4)$ & 171665 (23.6) & 5.3 \\
\hline DS performed prior to oral intake & $622718(78.7)$ & $54745(85.0)$ & $567973(78.2)$ & 17.6 \\
\hline \multicolumn{5}{|l|}{ Swallowing function } \\
\hline Unknown† & $171110(21.6)$ & 9929 (15.4) & $161181(22.2)$ & 17.5 \\
\hline Normal & $556869(70.4)$ & 31561 (49.0) & $525308(72.3)$ & 49.1 \\
\hline Dysphagia & $62832(7.9)$ & $22908(35.6)$ & $39924(5.5)$ & 80.3 \\
\hline \multicolumn{5}{|l|}{ Discharge outcomes } \\
\hline In-hospital mortality & $1662(0.2)$ & $1077(1.7)$ & $585(0.1)$ & 17.0 \\
\hline \multicolumn{5}{|l|}{ mRS score at discharge $\neq$} \\
\hline $0-2$ & $270649(34.2)$ & $10861(16.9)$ & $259788(35.8)$ & 43.9 \\
\hline$\geq 3$ & $119908(15.2)$ & $18957(29.4)$ & $100951(13.9)$ & 38.3 \\
\hline Length of stay, median (IQR) & $11.0(8.0-14.0)$ & $13.0(9.0-18.0)$ & $11.0(8.0-14.0)$ & 38.4 \\
\hline \multicolumn{5}{|l|}{ Region } \\
\hline Eastern & $367586(46.5)$ & $30417(47.2)$ & $337169(46.4)$ & 1.6 \\
\hline Central & $258162(32.6)$ & $15596(24.2)$ & $242566(33.4)$ & 20.4 \\
\hline Western & 165063 (20.9) & 18385 (28.5) & $146678(20.2)$ & 19.4 \\
\hline \multicolumn{5}{|l|}{ Hospital grade } \\
\hline Secondary & $307090(38.8)$ & $21597(33.5)$ & $285493(39.3)$ & 12.1 \\
\hline Tertiary & $483721(61.2)$ & 42801 (66.5) & $440920(60.7)$ & 12.1 \\
\hline
\end{tabular}

*The NIHSS score was missing in 157540 (19.9\%) cases.

†Unknown: Swallowing status was defined as unknown in patients without documentation of DS and those with missing swallowing function data.

¥The mRS score at discharge was missing in 400254 (50.6\%) patients.

.ASD, absolute standardised difference; CHD, coronary heart disease; DS, dysphagia screening; EMS, emergency medical services; MI, myocardial infarction; mRS, modified Rankin Scale; NIHSS, National Institute of Health Stroke Scale; PVD, peripheral vascular disease; SUs, stroke units; TIA, transient ischaemic attack. 
Table 4 Multivariable analysis of factors associated with pneumonia

\begin{tabular}{|c|c|c|c|c|}
\hline \multirow[b]{2}{*}{ Variable } & \multicolumn{2}{|c|}{$\begin{array}{l}\text { Patients with and without NIHSS } \\
\text { scores, } N=790811\end{array}$} & \multicolumn{2}{|c|}{$\begin{array}{l}\text { Patients with NIHSS scores, } \\
\mathrm{N}=633271\end{array}$} \\
\hline & OR $(95 \% \mathrm{Cl})$ & $P$ value & OR (95\% Cl) & $P$ value \\
\hline DS performed prior to oral intake & 1.47 (1.29 to 1.67$)$ & $<0.0001$ & 1.65 (1.41 to 1.92$)$ & $<0.0001$ \\
\hline \multicolumn{5}{|l|}{ Swallowing function, normal (reference) } \\
\hline Dysphagia & 7.31 (7.15 to 7.46$)$ & $<0.0001$ & 5.00 (4.88 to 5.13$)$ & $<0.0001$ \\
\hline Unknown & 1.52 (1.34 to 1.72$)$ & $<0.0001$ & 1.49 (1.28 to 1.74$)$ & $<0.0001$ \\
\hline Age (per 10 years) & 1.56 (1.55 to 1.57$)$ & $<0.0001$ & $1.53(1.51$ to 1.54$)$ & $<0.0001$ \\
\hline Male (vs female) & 1.15 (1.12 to 1.17$)$ & $<0.0001$ & 1.20 (1.17 to 1.23$)$ & $<0.0001$ \\
\hline Arrival by EMS & 1.84 (1.79 to 1.88$)$ & $<0.0001$ & $1.47(1.43$ to 1.51$)$ & $<0.0001$ \\
\hline Hospitalised in SUs & 1.17 (1.14 to 1.19$)$ & $<0.0001$ & 1.13 (1.10 to 1.15$)$ & $<0.0001$ \\
\hline \multicolumn{5}{|l|}{ Medical history } \\
\hline Stroke/TIA & $1.13(1.11$ to 1.15$)$ & $<0.0001$ & 1.09 (1.06 to 1.11$)$ & $<0.0001$ \\
\hline $\mathrm{CHD} /$ previous $\mathrm{MI}$ & 1.26 (1.22 to 1.29$)$ & $<0.0001$ & $1.20(1.16$ to 1.24$)$ & $<0.0001$ \\
\hline Atrial fibrillation & 1.68 (1.63 to 1.73$)$ & $<0.0001$ & 1.39 (1.34 to 1.44$)$ & $<0.0001$ \\
\hline Heart failure & 2.02 (1.91 to 2.15$)$ & $<0.0001$ & 1.92 (1.80 to 2.05$)$ & $<0.0001$ \\
\hline Dementia & 1.68 (1.54 to 1.83$)$ & $<0.0001$ & 1.57 (1.42 to 1.73$)$ & $<0.0001$ \\
\hline Smoking & $1.12(1.10$ to 1.15$)$ & $<0.0001$ & $1.13(1.11$ to 1.16$)$ & $<0.0001$ \\
\hline Hospital grade (tertiary vs secondary) & 1.17 (1.15 to 1.19$)$ & $<0.0001$ & $1.18(1.15$ to 1.20$)$ & $<0.0001$ \\
\hline \multicolumn{5}{|l|}{ Region, Western (reference) } \\
\hline Eastern & 0.70 (0.68 to 0.71$)$ & $<0.0001$ & 0.74 (0.72 to 0.76$)$ & $<0.0001$ \\
\hline Central & $0.58(0.57$ to 0.60$)$ & $<0.0001$ & 0.59 (0.58 to 0.61$)$ & $<0.0001$ \\
\hline Admission NIHSS score (per 1-point increase) ${ }^{*}$ & - & - & 1.08 (1.07 to 1.08$)$ & $<0.0001$ \\
\hline
\end{tabular}

The first column includes all patients; the second column is restricted to patients with admission NIHSS scores.

*Admission NIHSS score not included due to missing data in 157540 (19.9\%) of the patients.

CHD, coronary heart disease; DS, dysphagia screening; EMS, emergency medical services; MI, myocardial infarction; NIHSS, National Institute of Health Stroke Scale; SUs, stroke units; TIA, transient ischaemic attack.

Surprisingly, we found that DS and admission to SUs were associated with a higher likelihood of developing pneumonia, although these were likely not causal relationships. In our study, unknown swallowing function (ie, not having undergone DS) was also a risk factor for pneumonia, which supports the need for the timely performance of DS to prevent pneumonia. ${ }^{31}$

Similar to our results, the Get With The Guidelines (GWTG)-Stroke programme in the USA found DS to be associated with higher odds of pneumonia, likely because screening was performed in more patients with severe strokes. ${ }^{25}$ This association may also have been confounded by several other variables. First, the lack of effectiveness of dysphagia interventions may mask the positive effects of DS. Dysphagia status may also change several times during hospitalisation, and up to $16 \%$ of patients with dysphagia recovered within 5 days of stroke onset. ${ }^{32}$ In this study, DS was performed only prior to the first oral intake, which may lead to an overestimation of the prevalence of dysphagia in later phases of hospitalisation. Conversely, patients who are unconscious or receiving support via nasogastric tubes are not eligible for DS but are at high risk for pneumonia. ${ }^{33} 34$ They were not excluded from our study population, which may have led to an underestimation of the prevalence of dysphagia.

Organised SUs have been found to optimise poststroke outcomes. ${ }^{35}$ According to the guidelines, all patients who had acute stroke should be treated in SUs throughout their inpatient stay. ${ }^{36}$ In this study, patients who were treated in SUs were more likely to receive DS and more likely to develop pneumonia. We compared the characteristics of patients hospitalised in SUs and non-SUs (online supplemental table 1). Compared with those hospitalised in non-SUs, the group of patients hospitalised in SUs had a higher proportion of patients with an NIHSS score of 4-14 or greater than 15 and a higher proportion of patients who arrived by EMS. This suggested that patients in SUs are more severely ill than those in non-SUs. In the sensitivity analysis based on the presence of the NIHSS score on admission, the association between SUs and pneumonia was weaker than that in the original model that did not include the NIHSS score. This suggested that the association between SUs and an increased risk of pneumonia was somewhat confounded by the severity of stroke. In addition, the number of patients who were treated in SUs also affected this relationship; specifically, 
only one in five patients in this study were treated in an $\mathrm{SU}$, which was lower than the proportion reported in previous studies. ${ }^{37}$ Moreover, additional factors that could influence the development of pneumonia in patients with AIS, such as dysphagia management strategies and antibiotic therapy, were not documented in this study. Since the implementation of SUs in China in 2000, substantial progress has been made, ${ }^{38}$ but it is still a national priority to accelerate the certification of SUs and improve the medical quality in SUs. More research is needed to explain the relationship between dysphagia interventions in SUs and pneumonia.

Regional variations in the implementation of DS and the risk of pneumonia were observed in our study. Hospitals in the eastern and central regions had lower rates of DS than hospitals in the western region of China, but patients admitted to hospitals in the western region were also more likely to develop pneumonia. This may be due to the uneven distribution of medical resources, specifically the limited resources in hospitals in the western region, which leads to regional disparities in medical quality as well as different rates of developing pneumonia. CSCA and other quality improvement programmes should be further promoted in hospitals across China, especially those in the western region, to elucidate and eliminate regional disparities.

Our study included nearly 800000 participants from the CSCA, and the findings are likely generalisable to real-world clinical practice regarding DS and pneumonia in China. However, there were several limitations. First, hospitals voluntarily enrolled in the CSCA programme and were more likely to focus on improvements in stroke care quality, which may have led to an overestimation of stroke care quality when compared with a representative sample of hospitals in China. Second, the timing of pneumonia onset was not recorded in the database, which meant that cases that occurred prior to DS but within 48 hours of admission could not be excluded. This may have led to an overestimation of the incidence of pneumonia. Third, swallowing function is dynamic, and patients may have been screened several times during hospitalisation. As such, the temporal relationship between DS and pneumonia in our study may not be consistent across all patients. Additionally, there were no data on patients with disturbed consciousness, mechanical ventilation or diet during hospitalisation; these factors affect eligibility for DS. Due to the high incidence of pneumonia in patients receiving mechanical ventilation and nasogastric tubes in the ICU/NICU, ${ }^{39}$ patients admitted to the ICU/NICU were excluded from the analysis. However, some patients who were admitted to the ICU/NICU for other reasons, such as thrombolysis without mechanical ventilation or nasogastric tubes, were also excluded. Last, several confounding factors may not have been adequately accounted for in our analysis. Patients at risk of dysphagia would have undergone comprehensive dysphagia assessments, dietary adjustment or swallowing rehabilitation after DS, and these variables likely influenced the relationship between DS and pneumonia but were not available for inclusion in our models. The high rate of missing NIHSS scores also limited our ability to adjust for confounding by stroke severity.

\section{CONCLUSIONS}

Dysphagia is one of the strongest predictors of pneumonia, which in turn significantly affects the short-term prognosis in patients with stroke. DS has become a routine intervention for patients who had a stroke in China, but its implementation is inconsistent across regions, and the overall rate remains low. To reduce the incidence of in-hospital pneumonia among patients who had a stroke, the CSCA programme should be further promoted in hospitals across China, and the standardised management strategies for dysphagia should be refined. In the future, more observational studies with DS as the primary variable of interest as well as randomised controlled trials with interventions pertaining to training for swallowing function are needed to elucidate this issue and support the development of strategies to reduce the risk of pneumonia in patients hospitalised for stroke.

\section{Author affiliations}

${ }^{1}$ Nursing Department, Beijing Tiantan Hospital, Capital Medical University, Beijing, China

${ }^{2}$ Department of Neurology, Vascular Neurology, Beijing Tiantan Hospital, Capital Medical University, Beijing, China

${ }^{3}$ Department of Neurology, Vascular Neurology, China National Clinical Research Center for Neurological Diseases, Beijing Tiantan Hospital, Capital Medical University, Beijing, China

${ }^{4}$ Research Unit of Artificial Intelligence in Cerebrovascular Disease, Chinese Academy of Medical Sciences, Beijing, China

${ }^{5}$ China National Clinical Research Center for Neurological Diseases, Beijing Tiantan Hospital, Capital Medical University, Beijing, China

Acknowledgements We thank the CSCA collaborating centres, members, and volunteers for their hard work. We thank every participant who contributed invaluable data to CSCA.

Contributors All authors contributed to the conception, design, analysis and interpretation of the study. JL and $Z Y$ designed the study and wrote the manuscript. $\mathrm{HG}$ and $\mathrm{K}-\mathrm{XY}$ performed clinical data mining and data analysis. ZL, YW and YX contributed to the conception and design, drafting of the manuscript or revising it. CW was the guarantor of this study and was responsible for supervision of all activities. All authors commented on manuscript drafts and gave their approval for the final version to be published.

Funding The Ministry of Science and Technology of the People's Republic of China (National Key R\&D Programme of China, 2017YFC1310901, 2016YFC0901002, 2017YFC1307905, 2015BAl12B00), the National Natural Science Foundation of China (No. 81801152), Beijing Talents Project (2018A13, 2018000021223ZK03) and the Youth Programme (QML20180501).

Competing interests None declared.

Patient consent for publication Not applicable.

Ethics approval The study was approved by IRB of Beijing Tiantan Hospital, Capital Medical University (ID: KY 2018-061-02).

Provenance and peer review Not commissioned; externally peer reviewed.

Data availability statement Data are available on reasonable request. All data relevant to the study are included in the article or uploaded as online supplemental information. The data that support the findings of this study are available on reasonable request.

Open access This is an open access article distributed in accordance with the Creative Commons Attribution Non Commercial (CC BY-NC 4.0) license, which 
permits others to distribute, remix, adapt, build upon this work non-commercially, and license their derivative works on different terms, provided the original work is properly cited, appropriate credit is given, any changes made indicated, and the use is non-commercial. See: http://creativecommons.org/licenses/by-nc/4.0/.

\section{ORCID iDs}

Zhike Yin http://orcid.org/0000-0002-4855-8930

Hongqiu Gu http://orcid.org/0000-0003-1608-1856

Yunyun Xiong http://orcid.org/0000-0003-1353-2295

\section{REFERENCES}

1 Zhou M, Wang $\mathrm{H}$, Zeng $\mathrm{X}$, et al. Mortality, morbidity, and risk factors in China and its provinces, 1990-2017: a systematic analysis for the global burden of disease study 2017. Lancet 2019;394:1145-58.

2 Badve MS, Zhou Z, van de Beek D, et al. Frequency of post-stroke pneumonia: systematic review and meta-analysis of observational studies. Int J Stroke 2019;14:125-36.

3 de Jonge JC, Takx RAP, Kauw F, et al. Signs of pulmonary infection on admission chest computed tomography are associated with pneumonia or death in patients with acute stroke. Stroke 2020;51:1690-5

4 Braun T, Juenemann M, Viard M, et al. Adjustment of oral diet based on flexible endoscopic evaluation of swallowing (fees) in acute stroke patients: a cross-sectional hospital-based registry study. BMC Neurol 2019;19:282

5 de Montmollin E, Ruckly S, Schwebel C, et al. Pneumonia in acute ischemic stroke patients requiring invasive ventilation: impact on short and long-term outcomes. J Infect 2019;79:220-7.

6 Schwarz M, Coccetti A, Murdoch A, et al. The impact of aspiration pneumonia and nasogastric feeding on clinical outcomes in stroke patients: a retrospective cohort study. J Clin Nurs 2018;27:e235-41.

7 Pacheco-Castilho AC, Vanin GdeM, Dantas RO, et al. Dysphagia and associated pneumonia in stroke patients from Brazil: a systematic review. Dysphagia 2019;34:499-520.

8 Ouyang M, Boaden E, Arima $\mathrm{H}$, et al. Dysphagia screening and risks of pneumonia and adverse outcomes after acute stroke: an international multicenter study. Int J Stroke 2020;15:206-15.

9 Rugiu MG. Role of videofluoroscopy in evaluation of neurologic dysphagia. Acta Otorhinolaryngol Ital 2007;27:306-16.

10 Bax L, McFarlane M, Green E, et al. Speech-Language pathologistled fiberoptic endoscopic evaluation of swallowing: functional outcomes for patients after stroke. J Stroke Cerebrovasc Dis 2014;23:e195-200.

11 Eltringham SA, Kilner K, Gee M, et al. Impact of dysphagia assessment and management on risk of stroke-associated pneumonia: a systematic review. Cerebrovasc Dis 2018;46:97-105.

12 Palli C, Fandler S, Doppelhofer K, et al. Early dysphagia screening by trained nurses reduces pneumonia rate in stroke patients: a clinical intervention study. Stroke 2017;48:2583-5.

13 Powers WJ, Rabinstein AA, Ackerson T, et al. Guidelines for the early management of patients with acute ischemic stroke: 2019 update to the 2018 guidelines for the early management of acute ischemic stroke: a guideline for healthcare professionals from the American heart Association/American stroke association. Stroke 2019;50:344-418.

14 Winstein CJ, Stein J, Arena R, et al. Guidelines for adult stroke rehabilitation and recovery: a guideline for healthcare professionals from the American heart Association/American stroke association. Stroke 2016;47:98-169.

15 Li Z, Wang C, Zhao X, et al. Substantial progress yet significant opportunity for improvement in stroke care in China. Stroke 2016;47:2843-9.

16 Wang Y, Li Z, Wang Y, et al. Chinese stroke center alliance: a national effort to improve healthcare quality for acute stroke and transient ischaemic attack: rationale, design and preliminary findings. Stroke Vasc Neurol 2018;3:256-62.

17 Liu Z-Y, Zhang X-P, Mo M-M, et al. Impact of the systematic use of the volume-viscosity swallow test in patients with acute ischaemic stroke: a retrospective study. BMC Neurol 2020;20:154.
18 Horan TC, Andrus M, Dudeck MA. CDC/NHSN surveillance definition of health care-associated infection and criteria for specific types of infections in the acute care setting. Am J Infect Control 2008;36:309-32.

19 Austin PC. Balance diagnostics for comparing the distribution of baseline covariates between treatment groups in propensity-score matched samples. Stat Med 2009;28:3083-107.

20 Joundi RA, Martino R, Saposnik G, et al. Predictors and outcomes of dysphagia screening after acute ischemic stroke. Stroke 2017:48:900-6.

21 Wangqin R, Laskowitz DT, Wang Y, et al. International Comparison of Patient Characteristics and Quality of Care for Ischemic Stroke: Analysis of the China National Stroke Registry and the American Heart Association Get With The Guidelines--Stroke Program. J Am Heart Assoc 2018;7:10623.

22 Teh WH, Smith CJ, Barlas RS, et al. Impact of stroke-associated pneumonia on mortality, length of hospitalization, and functional outcome. Acta Neurol Scand 2018;138:293-300.

23 Zhang X, Yu S, Wei L, et al. The A2DS2 score as a predictor of pneumonia and in-hospital death after acute ischemic stroke in Chinese populations. PLoS One 2016;11:150298.

24 Teuschl Y, Trapl M, Ratajczak P, et al. Systematic dysphagia screening and dietary modifications to reduce stroke-associated pneumonia rates in a stroke-unit. PLoS One 2018;13:192142.

25 Masrur S, Smith EE, Saver JL, et al. Dysphagia screening and hospital-acquired pneumonia in patients with acute ischemic stroke: findings from Get with the Guidelines--Stroke. J Stroke Cerebrovasc Dis 2013;22:e301-9.

26 Hoffmann S, Harms H, UIm L, et al. Stroke-induced immunodepression and dysphagia independently predict strokeassociated pneumonia - The PREDICT study. J Cereb Blood Flow Metab 2017;37:3671-82.

27 Gittler M, Davis AM. Guidelines for adult stroke rehabilitation and recovery. JAMA 2018;319:820-1.

28 Zhang T, Zhao J, Bai YL. Guidelines for clinical management of cerebrovascular disease in China (excerpted version) stroke rehabilitation management. Chinese journal of stroke 2019;14:823-31.

29 Aoki S, Hosomi N, Hirayama J, et al. The multidisciplinary swallowing team approach decreases pneumonia onset in acute stroke patients. PLoS One 2016;11:154608

30 Maeshima S, Osawa A, Hayashi T, et al. Elderly age, bilateral lesions, and severe neurological deficit are correlated with stroke-associated pneumonia. J Stroke Cerebrovasc Dis 2014;23:484-9.

31 Smith EE, Kent DM, Bulsara KR, et al. Effect of dysphagia screening strategies on clinical outcomes after stroke: a systematic review for the 2018 guidelines for the early management of patients with acute ischemic stroke. Stroke 2018;49:123-8.

32 Abubakar SA, Jamoh BY. Dysphagia following acute stroke and its effect on short-term outcome. Niger Postgrad Med J 2017;24:182-6.

33 Harms H, Grittner U, Dröge H, et al. Predicting poststroke pneumonia: the pantheris score. Acta Neurol Scand 2013:128:178-84.

34 Wästfelt M, Cao Y, Ström JO. Predictors of post-stroke fever and infections: a systematic review and meta-analysis. BMC Neurol 2018;18:49.

35 Langhorne P, Ramachandra S, Stroke Unit Trialists' Collaboration. Organised inpatient (stroke unit) care for stroke: network metaanalysis. Cochrane Database Syst Rev 2020;4:D197.

36 Lou M, Ding J, Hu B. Guidelines for clinical management of cerebrovascular disease in China (excerpted version) - organized management of stroke. Chinese journal of stroke 2019;14:692-9.

37 Suntrup-Krueger S, Minnerup J, Muhle P, et al. The effect of improved dysphagia care on outcome in patients with acute stroke: trends from 8-year data of a large stroke register. Cerebrovasc Dis 2018;45:101-8

38 Tu W-J, Chao B-H, Yan F, et al. Stroke unit care for ischemic stroke in China: results of a nation-based study. Intensive Care Med 2020;46:1489-91.

39 Yeh S-J, Huang K-Y, Wang T-G, et al. Dysphagia screening decreases pneumonia in acute stroke patients admitted to the stroke intensive care unit. J Neurol Sci 2011;306:38-41. 